\title{
Developing Policy Pathways: Redesigning Transition Arenas for Mid-Range Planning
}

\author{
Sampsa Hyysalo ${ }^{1, *}$, Jani Lukkarinen ${ }^{2}{ }^{(0}$, Paula Kivimaa ${ }^{3}{ }^{-}$, Raimo Lovio ${ }^{1}$, Armi Temmes ${ }^{1}$, \\ Mikael Hildén ${ }^{2}$, Tatu Marttila ${ }^{1}$, Karoliina Auvinen ${ }^{1}$, Sofi Perikangas ${ }^{1}$, Allu Pyhälammi ${ }^{1}$, \\ Janne Peljo ${ }^{4}$, Kaisa Savolainen ${ }^{1}{ }^{(0)}$, Louna Hakkarainen ${ }^{1}$, Mikko Rask ${ }^{5}$, Kaisa Matschoss ${ }^{5}$ (), \\ Timo Huomo ${ }^{5}$, Annukka Berg ${ }^{2}$ and Mari Pantsar ${ }^{4}$ \\ 1 Aalto University, Otaniementie 14, 02150 Espoo, Finland; raimo.lovio@aalto.fi (R.L.); \\ armi.temmes@aalto.fi (A.T.); tatu.marttila@aalto.fi (T.M.); karoliina.auvinen@aalto.fi (K.A.); \\ sofi.perikangas@futurice.com (S.P.); allu.pyhalammi@aalto.fi (A.P); kaisa.savolainen@aalto.fi (K.S.); \\ louna.hakkarainen@naistenlinja.fi (L.H.) \\ 2 Finnish Environment Institute, Latokartanonkaari 11, 00790 Helsinki, Finland; \\ jani.lukkarinen@ymparisto.fi (J.L.); mikael.hilden@ymparisto.fi (M.H.); annukka.berg@ymparisto.fi (A.B.) \\ 3 University of Sussex, Sussex House, Falmer, Brighton BN1 9RH, UK; p.kivimaa@sussex.ac.uk \\ 4 SITRA, Finnish independence fund, Itämerenkatu 11-13, 00180 Helsinki, Finland; janne.peljo@sitra.fi (J.P.); \\ mari.pantsar@sitra.fi (M.P.) \\ 5 Consumer Society Research Centre, Faculty of Social Sciences, University of Helsinki, 00100 Helsinki, \\ Finland; mikko.rask@helsinki.fi (M.R.); kaisa.matschoss@helsinki.fi (K.M.); timo.huomo@gmail.com (T.H.) \\ * Correspondence: sampsa.hyysalo@aalto.fi
}

Received: 30 November 2018; Accepted: 14 January 2019; Published: 23 January 2019

Abstract: Sustainability transitions require new policy pathways that significantly reduce the environmental impacts caused by, for example, energy production, mobility and food production. Transition management (TM) is one of the approaches aiming at the creation of new ways to govern transitions. It uses transitions arenas (TA) as a key process and platform where new policy pathways are created in collaboration with multiple (frontrunner) stakeholders. TM's ambitious and demanding agenda is not easy to implement. There is a continued need for testing and developing new ways of carrying out its key processes. We redesigned the TA process in the context of energy system change in Finland by 2030, focusing on interim goals, mid-range change pathways and developing a new notation system that allows participants to directly create the pathways. The resulting renewed TA process results in more specific and detailed mid-range pathways that provide more concreteness to how to implement long-term transition goals. It helps to bridge long-term national visions/strategies and low carbon experiments that are already running. The Finnish TA work created eight ambitious change pathways, pointing towards new and revised policy goals for Finland and identifying specific policy actions. Evaluation of the TA, 6-9 months after its completion underscores that an effective TA needs to be embedded by design in the particular political context that it seeks to influence. It is too early to say to what degree the pathways will be followed in practice but there are positive signs already.

Keywords: transition management; transition arena; sustainability transitions; pathway; codesign; energy policy; mid-range planning

\section{Introduction: The Potential of Transition Arenas}

Sustainability transitions need to be urgently accomplished [1]. The growing discrepancy between globally agreed Paris targets for reduced temperature change and the actually realized country actions in addressing climate change mitigation emphasize the need to accelerate transition 
processes. Transitions generally benefit from, and may require, anticipatory action such as societal experimentation and policy changes [2-4]. Sustainability transitions are hence assumed to require public interventions that cross sectoral boundaries and also phase out unsustainable technologies and practices $[5,6]$. Often, alternative transition pathways-used in framing the challenge of moving towards more desirable futures, clarifying and stimulating transitions processes, and bridging perspectives [7] - are built to reach given sustainability goals [8]. Transition pathways describe realized or desired patterns of societal change needed to reach more sustainable socio-technical systems, that is, they provide routes for transformation in which specific actions by states and other actors are needed. Transition pathways are socio-technical and differ from biophysical and techno-economic pathways [7]. Within transition pathways, specific policy pathways are required to ensure that public interventions are directed to support the broader transition pathways. The concept of policy pathways has not been explicitly used in the transitions literature. Thus, we draw from Bernstein and Hoffmann [9], who in the context of climate experiments, describe policy pathways for decarbonization as a combination of political decisions, policies and voluntary decisions that (are needed to) influence technological and behavioral change.

The steering of systemic sustainability transitions has been investigated since the late 1990s in several multidisciplinary lines of research (e.g., [10-13]). Among the longest lines of research on transition steering is transition management (TM). TM was developed as an instrumental, practice-oriented model to advance sustainability transitions [14] in response to a perceived insufficiency of either governments or markets alone to tackle the complex changes needed to address persistent societal problems $[15,16]$. It developed in particular through the Dutch energy transition initiative $[16,17]$ and a range of regional and urban transition projects [18-20].

$\mathrm{TM}$ focuses on long-term socially inclusive policy designs by creating spaces for searching, learning and experimenting for relevant groups of 'frontrunner' stakeholders [16,17]. 'Transition arenas' (TA) play a key role in the strategic level of TM, including the development of long-term visions and goals and the identification of transition pathways [21]. The objective of the TA is to empower frontrunners with visions, concepts and seeds for thought to be utilized in decision making beyond the political cycle of elections. Experiments initiated by the transition arena network, including new institutional arrangements [22] and alternative policy pathways, are expected to produce alternatives that can be scaled up, strengthened and eventually displace the previously dominant unsustainable regime $[16,17]$.

However, political cultures and the dynamics of transitions make it necessary to critically consider and adjust the methodological approach, taking into account the specific context $[23,24]$. The adjustment may vary from different 'hybridizations' with related approaches to more profound reworking of the methodology [2]. The different realizations of TM can also contribute to theoretical development [2]. By building up empirical experience of TM processes, the approach can be critically revisited in order to understand also the challenges that TM has faced. These include the politics of societal learning, the contextual embedding, and the design of the TA (as one of the core elements of the TM framework). Voß et al. [25] (pp. 296-297) claim that "Only by keeping radical goals clearly in view can transition management overcome incrementalist shortcomings; envisioning radical changes in the long-term whilst recognizing that current structures and dynamics will influence the ability to get to that future." We argue that one way to tackle this challenge is to focus on mid-range, instead of just long-term, actions in formulating transition pathways and associated policy pathways. The focus on the mid-range implementation of transitional changes addresses the commonly perceived urgency in accelerating transitions in resource use and climate change mitigation. After the Paris agreement, most countries have long-term visions to carbon neutrality paired with relatively generic national roadmaps. Yet, input is lacking towards formulating more concrete pathways and pathway step-actions to be taken already in the medium term.

Transition pathways based on concrete, immediate and mid-range actions by policymakers and other stakeholders help ensure consistency between current and planned policy measures and identify 
which actions are needed immediately, and in the near future, to achieve long-term radical change. The specific context that we examine is the evolving framework of energy and climate policy in Finland. The official objectives, as framed at the start of 2017, were to, first, meet the European Union (EU) targets as implemented through the National Energy and Climate Strategy for 2030 [26] and, second, to proceed to more ambitious targets indicatively expressed in the Climate Roadmap 2050 [27].

In this paper, we describe how to set up a TA that communicates with the official targets and simultaneously challenges them, and goes beyond by formulating specific more ambitious and detailed transition pathways. In coordinating this process, we employed co-design tools and brought in results from existing energy transition experiments that show the potential for more radical changes than those embraced by the official policy.

The specific objectives of this paper are: (1) to discuss details on how the TA design was modified to fit the mid-range agenda and action setting in facilitating pathway creation; (2) to explain the design of this new TA version, with increased emphasis on pathway creation, for its possible further use in other contexts; and (3) to evaluate the TA process, focusing on outputs and impacts (social learning and network effects). In addition, as backdrop for these more general knowledge interests, the paper outlines the TA process for the medium term transition of the energy sector in the Finnish context and adds to the understanding of the key expectations that change makers have of the necessary energy sector transition.

The paper is organized as follows. Sections 2 and 3 explain the adapted design of the TA and contextualize the pathway creation tools and the challenges that had to be addressed. Section 4 provides an overview of the Finnish TA process and the policy and co-design redesigns it incorporated, and Section 5 discusses its outcomes. Sections 6 and 7 evaluate the outcomes of the process utilizing participant feedback immediately after and through interviews conducted 6-9 months later.

\section{Responding to Observed Challenges of Transition Management}

The original TM framework offers a prescriptive design as well as analytical tools for governing transitions [17]. It includes four sequential levels of activity [16,21]: (1) strategic activities including joint problem structuring, vision development, and long-term goal formulation, carried out by a transition arena(s) (TA); (2) tactical activities of agenda creation, negotiation and networking for coalition building and steering actions (e.g., financial support and programs); (3) operational activities on the ground, for example, experimentation, evaluation, and learning-by-doing; and (4) reflexive, cross-cutting activity across the three other levels leading to modified visions, or experimental designs. In TM, the process of constructing pathways for meeting the long-term vision and specific transition goals is emphasized, with the aim to foster intersectional dynamics encouraging transformative change.

The transition arenas initiate the TM and, in the TA(s), groups of stakeholders envision and build transition visions, goals and pathways of change, and suggest immediate actions to be taken. In addition, the TA process aims at learning among the participants, so that the "actors involved will adjust their own problem definitions and perceptions because of a better understanding of the nature of the problem and the perspectives held by other actors and accordingly their behaviour" [15] (p. 113).

The original TM focus was on long-term change. In the appraisals of the first wave of TM studies a decade ago, Kern and Howlett [28], Voß et al. [25] and Heiskanen et al. [2] identified several important challenges that needed consideration in practical applications. These included, for example, avoiding the dominance of powerful incumbent actors in the TAs and opening up the deliberations to representatives from the civil society, ensuring that the focus is not only technological but broadly socio-technical $[25,28]$. The particular context in which the process is applied was also identified to need greater attention [2,29]. In the context of urban TM applications, related challenges have been found, including tensions between existing plans and new transition agendas, resistance to imposed transition thinking and methodology [30], and how well TA processes are coordinated regarding policy windows [31]. In the worst case, TM can become a 'disempowerment' process [23]. The proliferation of TM and TA processes in different country contexts and settings currently also calls for local adjustments 
to revitalize the TM agenda as an adequate participatory socio-technique that does not lapse into instrumentalist repetition of the process despite of local specificities and aims [32].

Despite the recent advances, Voß et al [25] assessment of the TA framework, and their call for specific responses to 'redesign transition management' to address its challenges, remain valid. These include the establishment of principles and guidelines for the selection of participants and the moderation of interaction processes to ensure broad participation of actors who co-produce a new system and those who are affected; the construction of visions by participants to make visible tensions between normative desires, feasibility considerations and creativity; and the negotiation of evaluation criteria for broad societal implications of alternative pathways to sustainable development, learning from experiments and embedding the overall process in democratic institutions. In addition, they argued that policy design should be regarded as an innovation process, with work towards the realisation of objectives by continually designing in context. Below in Section 3 we use these dimensions to elaborate and motivate in detail our own set of responses to TM challenges considering the specificities of the Finnish context but aiming at more general contribution to transitions theory. Our focus is on the TA, because, on the one hand, it is a core distinct activity in TM and, on the other hand, as we argue below, the other aspects of TM-such as experiments, long-term visions and social learning mechanisms - may in fact already find existing alternative mechanisms in specific contexts (Figure 1). We will, thus, next discuss our solutions to the challenges in Section 3 (and their evaluation in Section 7).

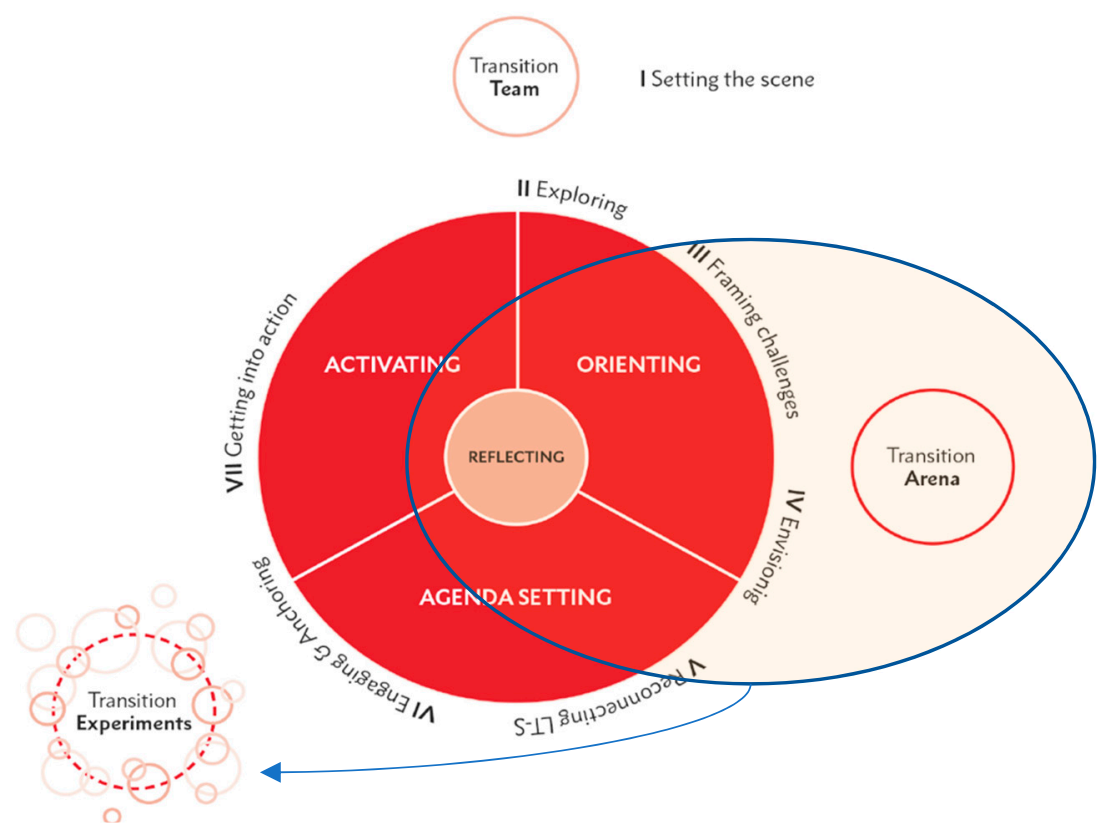

Figure 1. The Finnish process focused on redesigning transition arenas, addressing the orienting and agenda setting phases of transition management (TM) methodology.

\section{Research Method: An Energy Transition Arena for the Finnish Context}

The Finnish TA involved 23 invited stakeholders (i.e., change makers) (see Section 5), and 16 researchers who conducted tasks for planning and designing the TA and facilitating and documenting the discussions. The researchers were from several research organizations that formed the Smart Energy Transition consortium; the organizers were not affiliated with any political party/process or government agency.

The main research material that we explore in this study is: (1) the co-creation process including six half-day workshops, a kick-off meeting and the final report launch event during February-November 2017; (2) a survey to the participants after the last workshop in October 2017 with 19 responses 
(Appendix A, Table A1); and (3) 21 interviews conducted during April-August 2018 with the TA participants (Table A2). The Finnish TA process is elaborated further in Section 4.

To translate the TA process adequately to the Finnish context, the author group developed a set of responses to address the critical issues highlighted by Voß et al [25] and others on the known shortcomings of previous TA processes (Section 2). These design choices build on the author groups' long and deep knowledge of Finnish climate and energy policy, business and consumption, trials with transition governance tools in the 2000s, and extensive experience in developing other deliberation and codesign arrangements. In the following the choices that were made are elaborated against the evaluation framework of Voß et al [25].

Goals of the transition arena: Finland has established national roadmaps for long-term (until 2050) and mid-range (until 2030) climate and energy planning. There are also around 150 documented experiments related to the energy transition. However, there has been a lack of means to connect the visions and goals presented in the policy strategies with the on-the-ground experiments and other specific actions within the mid-range timeframe. To overcome this, the TA was designed to focus on the mid-range timespan of 13 years that allows elaborating more specific and concrete actions and pathways.

Organization of the transition arena: The transition arena was planned to run throughout one year. The frontrunners who participated in the arena were selected from among 90 change makers who were identified as most relevant by the involved researchers based on their extensive knowledge of Finnish energy and climate governance. The selection of invitees was based on their competences and complementarities regarding the Finnish energy and innovation systems and on finding a balance between 'incumbents' and 'newcomers'. Personal invitations with one-page explanation were sent to 25 people, out of which 23 agreed. The group included representatives of Finnish political, public administration, business, and civil society actors (Table A3). The participants were expected to provide a variety of perspectives on the topics and also benefit by forming new connections for their change initiatives. To mitigate for the dominance of incumbents, the selection of participants from incumbent organizations excluded actors who had prepared the scenarios for national energy strategies or would be primarily occupied with present day business operations. Instead, participants from the incumbent organizations were invited from $R \& D$ and innovation divisions that had longer term perspectives and weaker ties to the status quo of the incumbent energy regime.

Embedding in the political context: To embed the TA process in the national political culture participants included a representative from the Finnish Parliament's cross-party 'energy renovation' group, four high level civil servants from key ministries and offices, a Mayor of one city and a chief environmental officer from another city. Further embedding was sought through anchoring the transition arena vision and goals with the 2030 timeframe, which corresponds to the national mid-range climate plan and energy and climate strategy. The explicit temporal link made the proposals of the TA comparable with those debated in the institutionalized processes, including discussions in Parliament.

Role of visions: In the original TM, the building of shared visions to guide transition processes is strongly emphasized. In Finland, national, long-term low-carbon visions exist for 2050. Several cities and municipalities have also produced visions for 'carbon neutrality'. In addition, mid-range planning is conducted through national energy and climate strategies drafted or revised by each government approximately every four years, the latest published in late 2016. Given these specificities, it was decided to focus on a mid-range 'interim vision' until 2030 and to formulate 2030 transition goals. While the 2016 Energy and Climate Strategy 'vision' or goals were taken as a starting point, they were discussed and reformulated in one of the workshops and two rounds of commentary.

Experimentation: The latest Finnish government program aims to create a 'culture of experimentation' to improve new policy development including extensive trials and several smaller experiments, systematic experimentation and a legal basis to support the management of experiments [33]. In addition, many companies and civil society actors have already been busy creating 
experiments related to energy transition. An important starting point for the transition arena work was a database of over 110 energy transition related experiments, demonstrations and pilots, which had been generated in the Smart Energy Transition Consortium [34]. Thus, documented experiments could be linked to the transition pathways to be explored. In turn, the TA was hoped to provide impetus for new experiments and discussions on how they would temporally and spatially link with ones already ran by various private, public and civil society actors.

Evaluation and Learning: The transition arena featured evaluation by the participants after each workshop and at the end of the process, when also the codesign toolsets were evaluated in more detail. The participants wished to convene six months after the launch of the TA report to exchange thoughts on how the envisioned actions had progressed and whether there would be opportunities to coordinate actions to further the next steps. In conjunction with this half year event, interviews were carried out with 21 out of the 23 participants $6-9$ months after the last TA meeting to evaluate the process and its outputs, and potential broader outcomes and learning (see Section 6).

Sources of legitimacy: Legitimacy for the transition arena process was built through a set of complementary measures. First, the Smart Energy Transition consortium contacted the low carbon circular economy theme of the Finnish Innovation Fund Sitra to co-host the process at their premises. Established by the Parliament in 1967, Sitra holds a position of an independent future house, and the transition arena was a legitimate course of action for its low carbon thematic area. Sitra is a highly esteemed transition intermediary actor [35]. Second, the wide and carefully considered cast of participants was paired with equal care in communications and reporting. The final report was handed over to a Finnish Cabinet Minister known to be active in energy transition and several meetings and discussions were held to include those stakeholders who were not part of the arena process, including key incumbents.

Participation process support: When acquainting themselves with the TM methodology and guides, the codesign experts in the author group noticed that the highly ambitious deliberation processes featured rather rudimentary support instruments for collaborative work. Albeit codesign is mentioned as an area from which TM draws, its long development of means and procedures to augment deliberation has been utilized far below its potential (cf. [36-39]). The need for improved instrumentation was underscored by the mid-range focus, which would arguably entail more concrete pathway steps and actions. The involvement of high-level change-makers in the Finnish society meant working with limited attainable timeslots. These challenges were met by building tools that would support multi-actor deliberation in concrete and fast-paced workshop settings aiming for mid-range considerations [40].

\section{Operationalization of Mid-Range Focused Transition Arena in Helsinki 2017}

The number and content of TA workshops was subject to a long debate among the authors during the set-up phase of the Finnish 2017 arena. TM manuals suggest as many as 10-14 days in total (e.g., Roorda et al. [19] but see reports on shortened procedures in Ferguson [41]). The policy and business experts among authors stressed that a much more compressed structure was needed to ensure that the sought-after busy participants would turn up. Eventually a structure of six half-days was created (Table 1). Within this structure, the core design principle of focusing on the concrete mid-range pathways meant that pathway formation came to comprise $2 \frac{1}{2}$ of the total six workshops. The temporal compression further meant that support techniques developed in codesign were extensively used across all the workshops, and the toolsets were designed to augment the pathway creation work [40]. In addition to using templates, pre-tested time-boxing was used for each task (identification of drivers and challenges, creation of vision and goals, formation of pathways). 
Table 1. The Transition Arena (TA) Process.

\begin{tabular}{|c|c|c|}
\hline Workshop Number and Topic & Main Contents & Outputs \\
\hline $\begin{array}{l}\text { 1. The drivers, challenges } \\
\text { and contingencies } \\
\text { for transition }\end{array}$ & $\begin{array}{l}\text { Discussion on key features to be } \\
\text { taken into account in aiming for } \\
\text { an energy transition }\end{array}$ & $\begin{array}{l}\text { Compiled lists of drivers, } \\
\text { challenges and contingencies }\end{array}$ \\
\hline $\begin{array}{l}\text { Vision and transition goals } \\
\text { for } 2030\end{array}$ & $\begin{array}{l}\text { Formulation of explicit concrete } \\
\text { goals that can be quantified } \\
\text { and measured }\end{array}$ & $\begin{array}{l}\text { - } \quad \text { Vision statement } \\
\text { - Transition goals for } \\
\text { pathway work }\end{array}$ \\
\hline $\begin{array}{l}\text { Formation of pathways, } \\
\text { part } 1\end{array}$ & $\begin{array}{l}\text { Identification of steps, actions } \\
\text { and sequences along the } \\
\text { transition pathways, where } \\
\text { policy pathways intertwine with } \\
\text { broader transition pathways }\end{array}$ & $\begin{array}{l}\text { - Initial pathway designs } \\
\text { on boards } \\
\text { Memos of results that } \\
\text { accompanied } \\
\text { pathway visualizations }\end{array}$ \\
\hline $\begin{array}{l}\text { 4. Formation of pathways, } \\
\text { part } 2\end{array}$ & $\begin{array}{l}\text { Diversifying and complementing } \\
\text { the pathways with critical } \\
\text { junctures, links between actions }\end{array}$ & $\begin{array}{l}\text { - Finalized pathways designs on } \\
\text { boards and on-line } \\
\text { - } \quad \text { Iterated memos of results }\end{array}$ \\
\hline $\begin{array}{l}\text { Finalizing pathways and } \\
\text { Immediate actions in } \\
\text { the pathways }\end{array}$ & $\begin{array}{l}\text { - Finalizing and commenting } \\
\text { pathways; learning café } \\
\text { Priorities for change actions in } \\
\text { order to proceed along } \\
\text { the pathways }\end{array}$ & $\begin{array}{l}\text { - Final comments on } \\
\text { pathway designs } \\
\text { - Compiled lists of } \\
\text { change actions }\end{array}$ \\
\hline $\begin{array}{l}\text { 6. Completing the results and } \\
\text { commenting on the } \\
\text { final report }\end{array}$ & $\begin{array}{l}\text { - Comparisons across pathways, } \\
\text { identification of key actions }\end{array}$ & $\begin{array}{l}\text { - Comments and suggestions for } \\
\text { final reporting and identified } \\
\text { key actions }\end{array}$ \\
\hline
\end{tabular}

The participants were subdivided into small groups of 4-8 people (depending on task). The composition of the groups was partly rotated during the process. Each group had facilitators who recorded and transcribed the group's discussions to ensure sufficient knowledge capture. A digital in-between-workshops commentary process was introduced to share and refine the outputs from one workshop to the next.

The first two workshops relied on an often used codesign structure where each topic-drivers of change, present challenges, contingencies, vision for 2030 and transition goals for 2030 in this order-was first openly discussed in each subgroup, after which each participant wrote down individually the items that needed consideration and shared them in the subgroup. The items were then prioritized by voting in subgroups and then across all groups. These resulting priority lists were collected and edited for clarity by the organizers and opened for digital commentary or voting and thereafter for plenum discussion in the beginning of next workshop.

The organizing team was uneasy about the fast-pacing of these procedures, yet the interim and ex-post evaluations showed that most participants were very satisfied with the structured procedures, even though some found them stressful. They felt that the issues discussed were deeply familiar to them and that the procedures ensured that all the important perspectives became expressed without 'excessive oratories and inability to move beyond agreeing on definitions in other energy and climate related workshops previously' (oral feedback to an organizer midway through the arena process).

A more thoroughgoing design of toolset for creating mid-range transition pathways was a precondition for effective work on the policy pathways. This toolset 'transition pathways canvas' was a set of predefined forms and categories that are placed and operated on a $250 \mathrm{~cm} \times 120 \mathrm{~cm}$ vertical metallic board onto which the magnetic elements attach. These elements-pathway steps, arrows and pathway step realization actions-all have a pre-structured writing surfaces on which 
participants could add content with markers. The magnetic elements enabled easy rearrangement of the pathways and the board size allowed $3-5$ people to work jointly effectively (Figure 1). The choice of hexagon-shaped elements, descriptive labels and color coding was based on their common use ideation systems that utilize the cumulative capacities in honeycomb structures [42].

The interrelations between elements were clarified with magnetic arrows, which allowed writing onto them. The mid-range pathway workshop moved from discussing the target and pathway on a general level to concretizing pathway steps by naming and placing the elements on the board. As 'change steps' cumulate, discussions move to their ordering, interrelations and potentially missing steps. The pathways were typically rearranged several times and sub-pathways emerged, either from the onset or through the branching of the pathways. Thereafter deliberation typically focused on the need, realism and sufficiency of the steps for reaching the transition goal. Once the main pathway steps found an agreed form, the participants moved on to identifying the most crucial steps and likely blocking points. These formed the focal points for the second stage where "pathway step actions" for realizing each of these strategic pathway steps are identified. These were marked adding specific tablets around pathway steps. These tablets included 'technology development', 'regulation', 'end consumption', 'pilots', 'investment', 'energy production', 'business' and 'other'. (Figures 2 and 3)

The final two phases of the process first examined the uncertainties and contingencies related to the pathway, which proceeded by shifting from the blue coloring markers and arrows used in creating the main pathway into green ones that marked uncertainty and resilience related issues and by adding in probability markers of varying lengths to each pathway step and, where necessary, adding in associated contingency measures as new pathway steps. After this, focus was shifted to alternatives to the main pathway for reaching the transition goals. These alternative pathways were created by adding in red marked steps and red arrows where relevant, indicating either bifurcations or joining of paths.

Once the pathway was complete it was digitized and uploaded for commentary. The digitization allowed cleaning and the opening of all content as full sentences that are understandable to those beyond the participants involved in pathway creation as well as easy location independent commentary via the digital platform (see Figure 4 for a completed pathway).

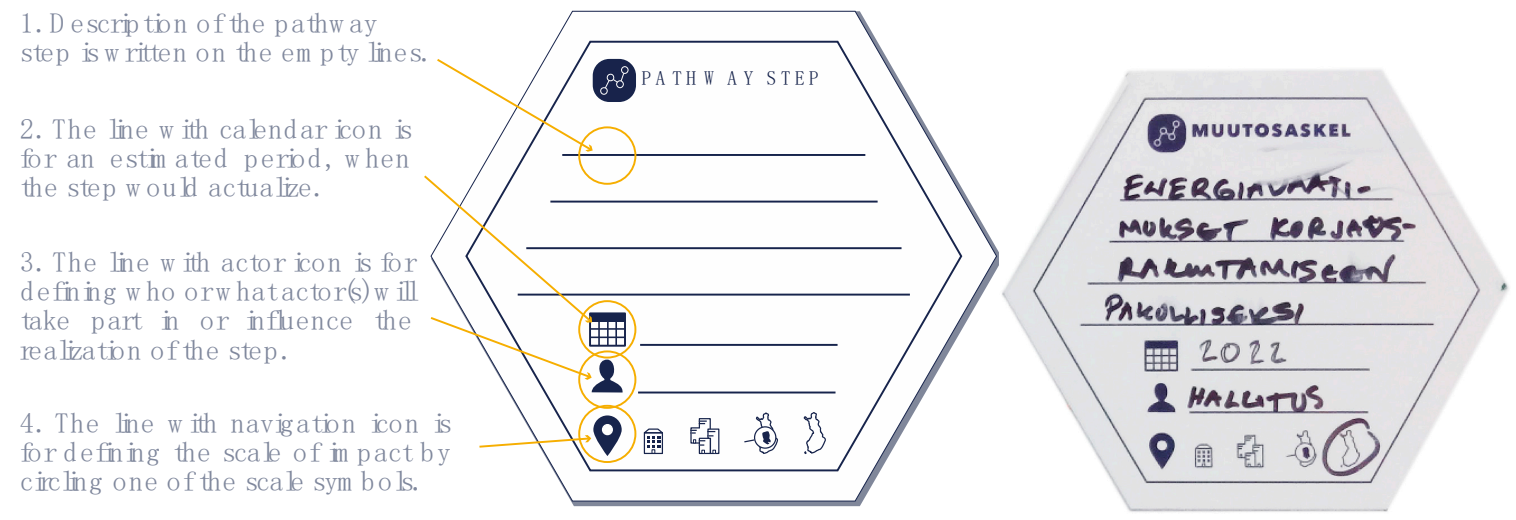

Figure 2. A pathway-step element and an example of a filled-in pathway step (in Finnish). 


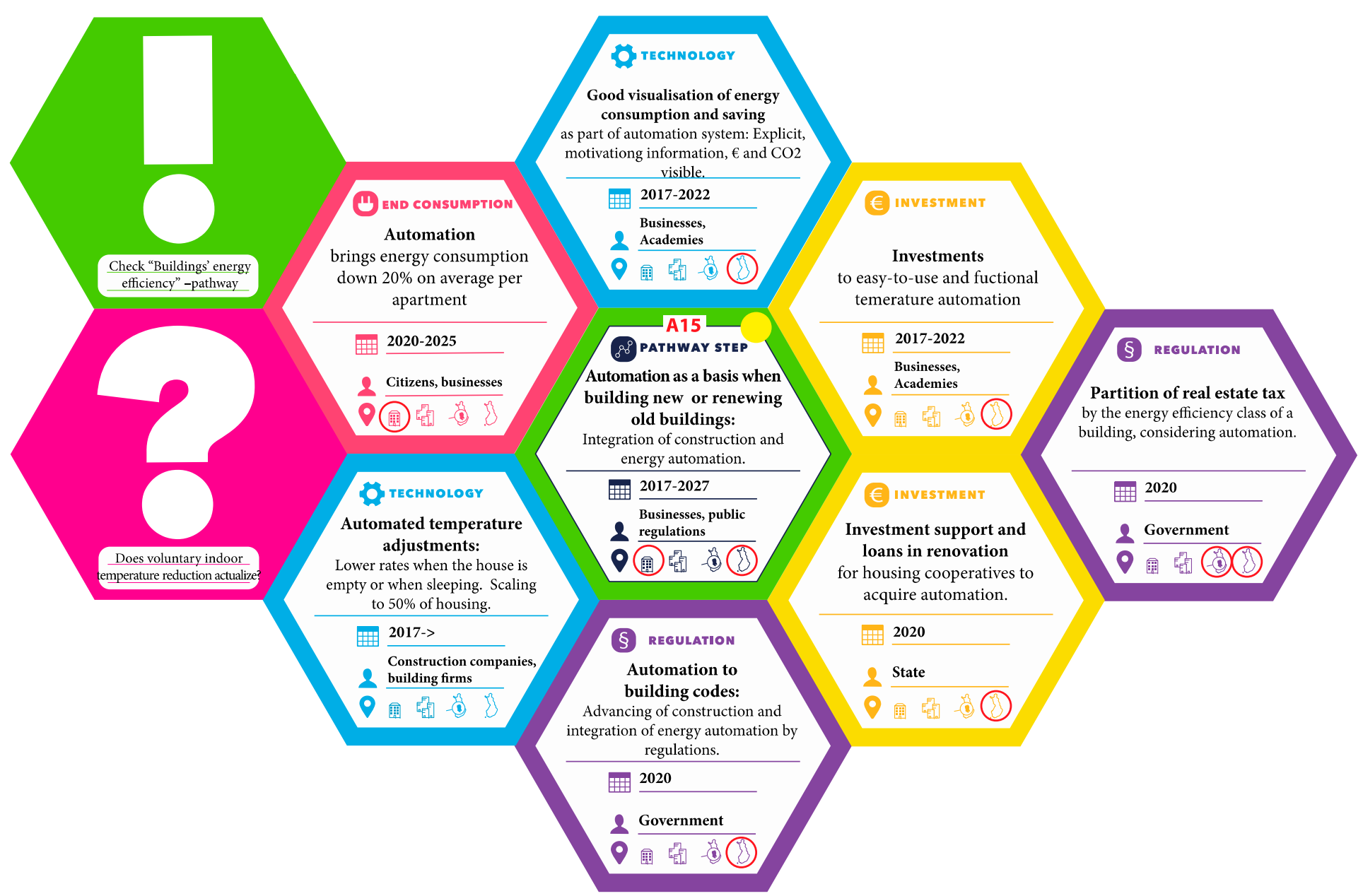

Figure 3. An example of a pathway step 'automation as a basis when building new or renewing old buildings' around which facilitating actions have been identified: blue for technology, yellow for investments, lilac for regulation and red for drivers. The green exclamation mark notes a link to another pathway and the red question mark a major uncertainty (translated by the authors). 


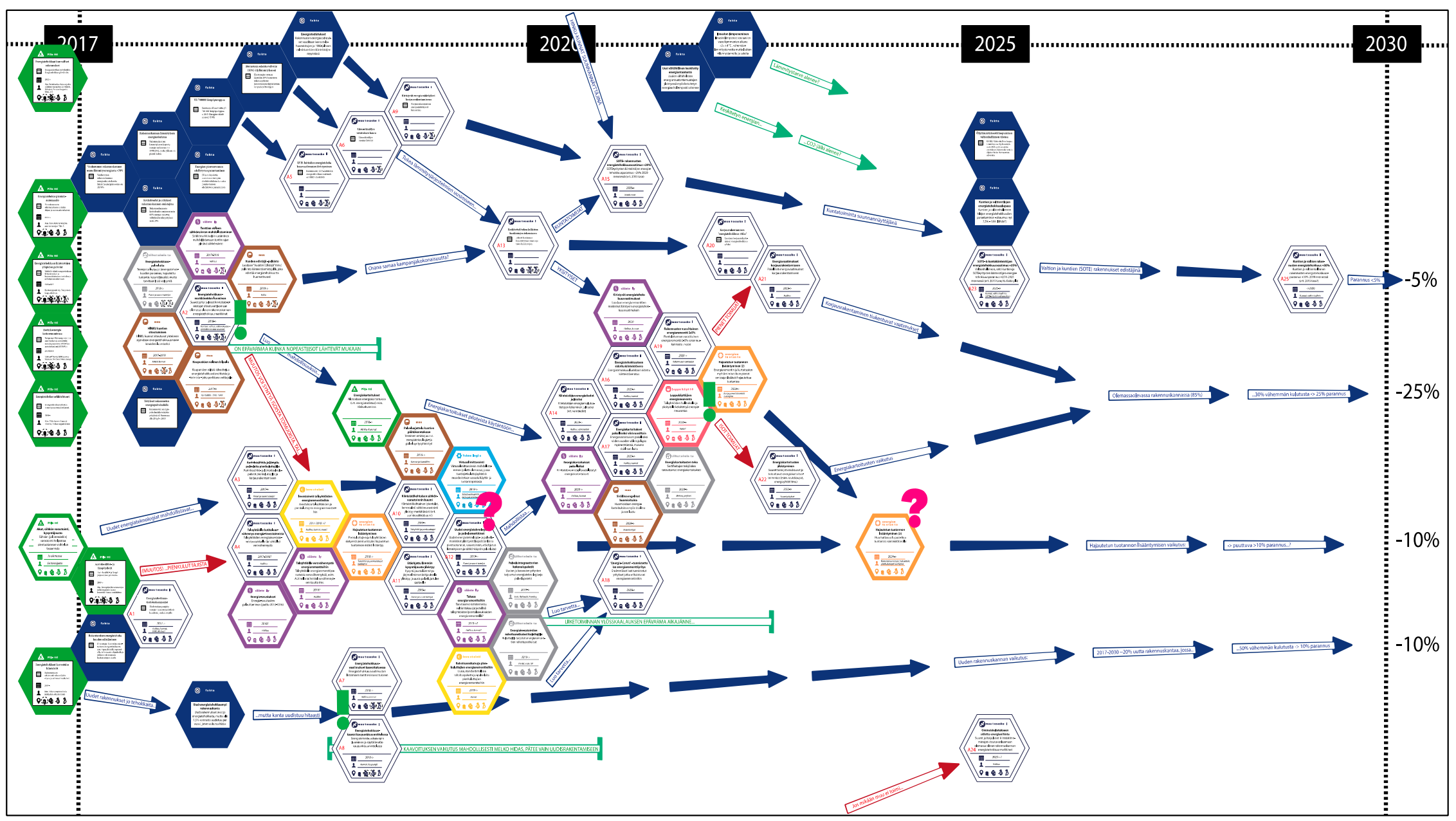

Figure 4. The final digitized path for halving a building's net-energy use by 2030. Different paths contribute to specific percentage reductions. For example, 10 percentage units of the halving is attributed to a path that ensures the energy efficiency of all new buildings. 
These procedures were codified into participant and facilitator digitization guides, a digital platform and templates for digitalization, which could, in turn, be used in the final reporting format of the arena process $[40,43]$.

\section{Main Results and Key Outcomes of the Finnish Mid-Range Transition Arena Process}

The arena produced a range of outcomes: it articulated a more ambitious and inspiring energy and climate vision for Finland in 2030; it created an understanding of the change drivers, impediments and uncertainties in achieving an ambitious energy vision; identified thirty intermediate goals for 2030; and created eight detailed pathways of change for the most important transition goals (Figure 5), and identified over one hundred actions to be taken along these pathways. The amount of information created is considerable. Even when heavily condensed, the process amounted to a 200-page report [43].

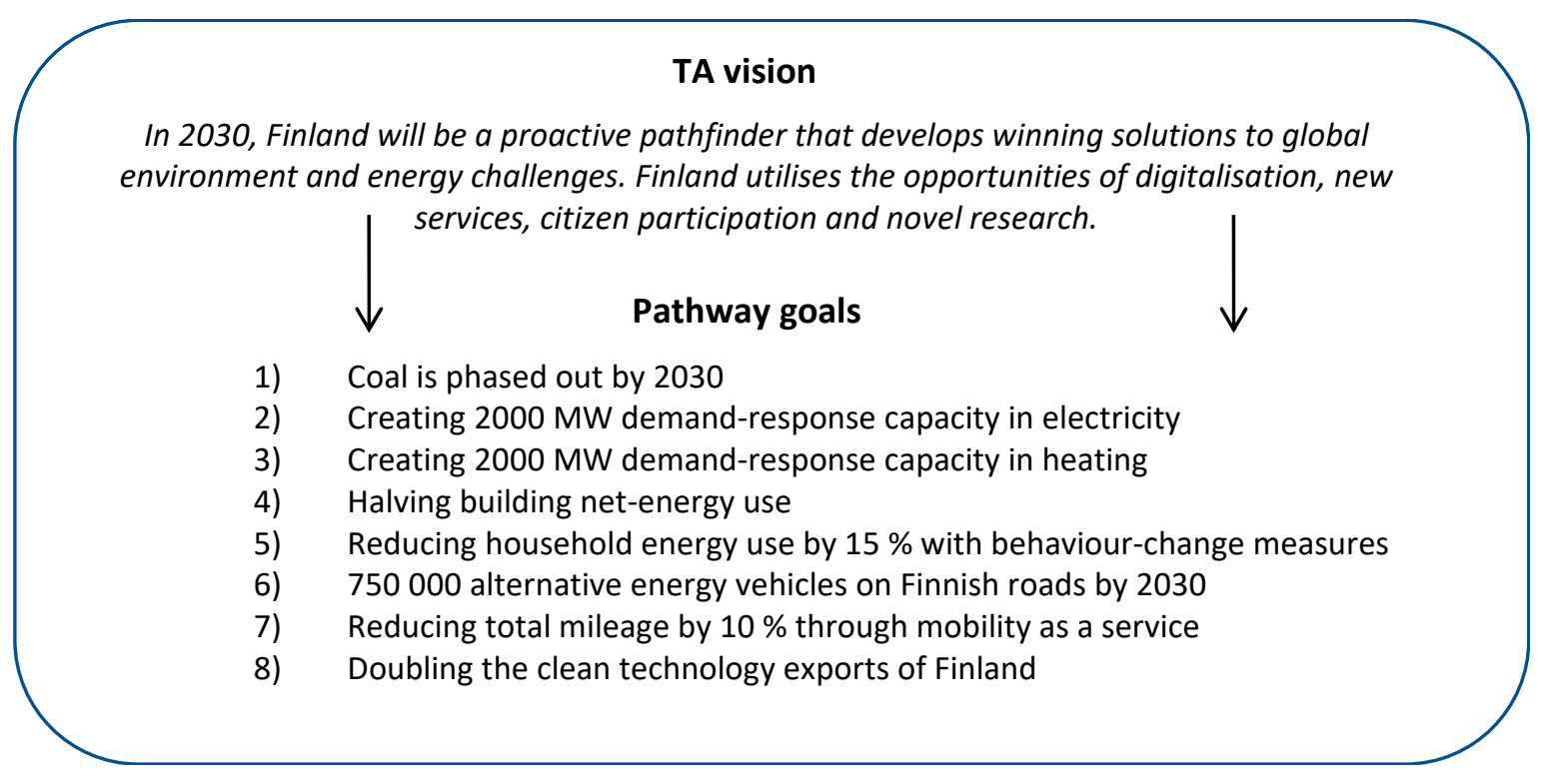

Figure 5. The vision and pathway goals produced in Helsinki TA process.

The pathways to 2030 (Figure 5) varied in terms of novelty. Some built on a fair number of background studies that could be used to ground the work and some of the participants had already worked with the topic, such as the promotion of electric cars. Others, such as the ambitious ' $15 \%$ energy consumption reduction through behavioral change' or the 'doubling of cleantech exports', had a weaker existing fact base to build on. As a consequence, these pathways included new ideas of what steps might be sufficient and feasible (even in principle) in order to reach the transition goal.

The final report [43] was released to a Cabinet Minister in November 2017 in an event featuring a panel of MPs and 100 invitees from ministries, businesses, civil society and academic organizations. The report was featured on headline TV news, morning TV and in 16 newspaper articles, which basically covered all the relevant major Finnish media. It received 250 posts in a "new energy policy" social media discussion group, and 30 related blogs and several columns appeared authored by the participants.

There has also been considerable interest from other actors. Several discussion invitations from both regime and niche actors have followed. A decision to launch four new transition arenas (urban energy strategy, energy citizenship and two on regional blue economy) has already been made. The participants to the 2017 Helsinki arena also wanted to hold a follow-up meeting in May 2018 to see if any further coordinated actions were needed and could be ideated among them.

It is too early to assess the policy impact in light of realized actions as it is only a year from the end of the arena and policy processes tend to take considerable time. Moreover, actions by policy makers and private companies are seldom causally hardwired to any one event but result from multiple input 
and complex (quasi-)causational paths. The role of successful participative mechanisms is not only in potentially initiating change but acting as settings to which participants can bring their ideas, elaborate them, gain reactions from other participants and take them onwards to next action-sets [31].

Regarding the Finnish arena, several such potentially affected actions-sets can already be identified. For instance, the opening of district heating networks to third party heat production was identified in the TA as one of the most significant actions to expedite energy transition-currently large Finnish cities use combined heat and power (CHP) from fossil fuels and mere substitution by biomass remains problematic. Thus, moving district heating towards increased use of non-carbon sources, such as waste heat and heat pump-produced heat, is needed and this calls for third party access to the networks. Four months after the arena, in March 2018, the second largest incumbent district heating company Fortum opened major municipal district heating networks for third party waste heat and clean energy producers in in five cities. The Energy Utility Helen, in charge of the Finland's largest heating network, initially opposed the idea of opening district heating networks to third party producers of heat but changed its position and has initiated a campaign to buy waste heat [44].

As another example, the Ministry of Transport and Communications published its transport pathways report in the end of 2018, where it had raised the 2030 target of alternative motive force vehicles to 800,000 from an earlier number, 300,000, in line with the pathway formed in the TA process with many same pathway steps and step-actions [45]. Finally, following the UN climate negotiations in Katowice, eight out of nice largest political parties in Finland pledged to tighten Finland's 2030 greenhouse gas reduction target from $40 \%$ to $55 \%$ of the 1990 level and aimed at carbon neutrality during the 2040s. This is also exactly in line with the demands presented through the TA process. Clearly, however, the TA process has been but one of the many settings where this change has been advocated.

\section{Evaluation of the Transition Arena Process and Early Impacts}

The evaluation of the transition arena examined the process and early impacts through participant input. We adapted the categories of Schäpke et al. [46] on the effects of transdisciplinary transition management processes to identify focal areas of the evaluation (Figure 6). We, thus, focused on: (1) process experiences; and (2) capacity increases and network effects. We also gauged more tentatively whether the TA had already resulted in outcomes in terms of collective action and changed decision-making. The evaluation of possible structural change was not considered feasible only six months after the closing of the TA process.

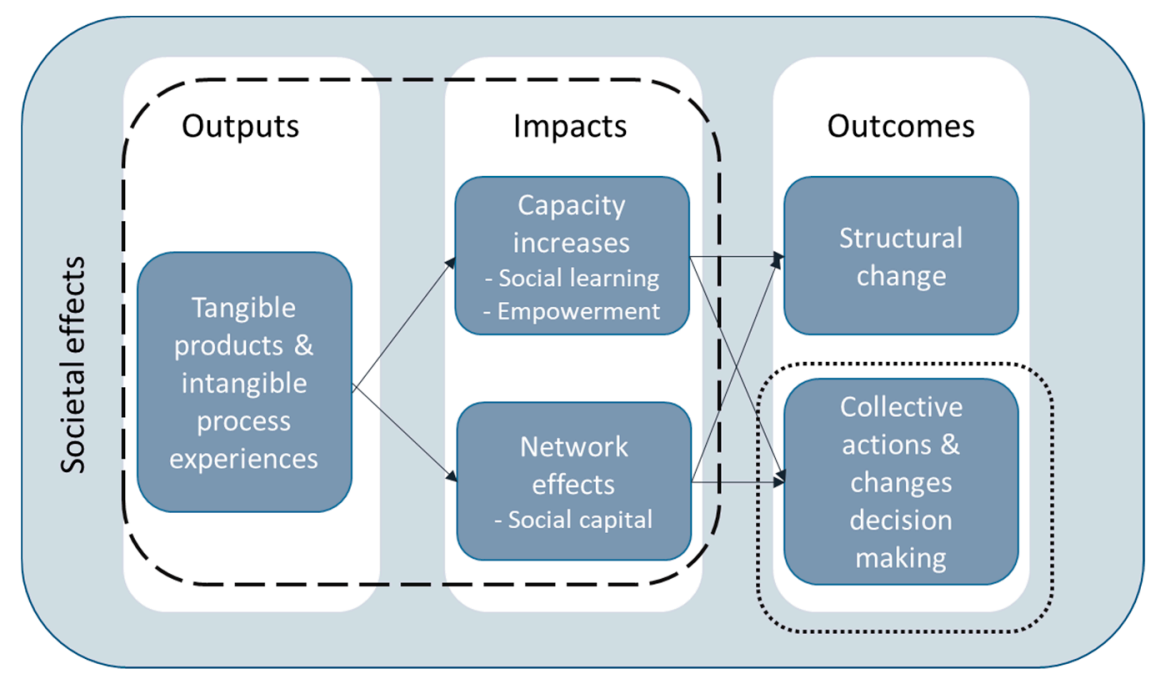

Figure 6. Focus areas of participant evaluation (dashed line) and tentative considerations (dotted line), figure adapted from Schäpke et al. [46]. 
Our evaluation used as material responses to a questionnaire at the end of the arena work, received during October-November 2017, as well as interviews with the transition arena participants in person or via the phone (12-55 minutes in duration) in April-August 2018. The aim was to detect how the participants viewed the process, the impacts of the arena work on a personal level (new ideas, learning, and changes in perception) as well as broader impacts and outcomes via effects on the participants' work communities, action taken on the basis of new ideas, further distribution of learning and ideas, new contacts made, further applicability of the TA process, and evidence of impact on policymaking. Appendix A shows the questions and results of the survey and the interviews.

\subsection{Process}

The process evaluation provided an overview of how the transition arena work and its distinct phases were regarded by the participants (Figure 7). On a scale from 1 to 5 , in the survey, the participants considered the arena work worthwhile (4.21 average) and inspiring (4.00 average). The open replies to the survey responses were generally positive regarding the intuitive and creative design of the process and the professional level of facilitation, while the more skeptical comments concerned the first two workshops (system framing, visioning) and the mobilization of outcomes. Other, repeated positive comments concerned the diverse selection of participants, and the critical comments concerned mostly the time constraints of the participants. Of the process components/outputs, the final report was rated the highest (4.00 average), the pathway work second (3.68 average) and the visioning lowest (3.53 average).

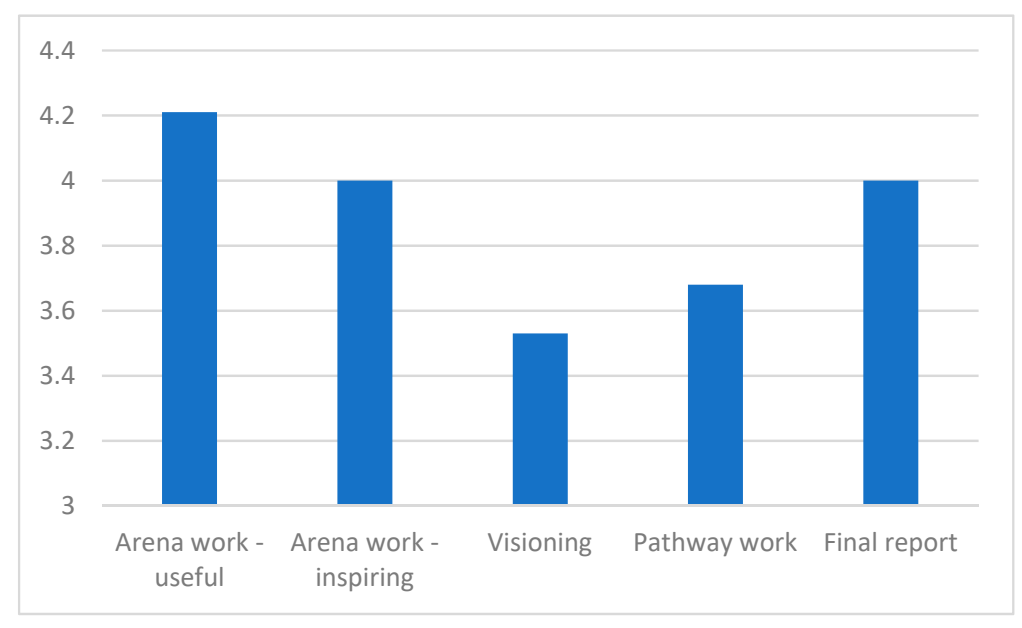

Figure 7. Rating of arena process by participants (scale 1-5).

The findings of the structured interviews conducted 6-9 months after the TA process broadly confirmed the survey results. Thirteen (13) participants specifically mentioned that the TA was well designed and 7 participants brought up the excellence of facilitation. About a half (11) remarked that the selected group of participants was good and worked well. Yet, some viewed that the work suffered from a lack of dedication on behalf of some participants and that some key stakeholders were missing. The survey responses highlighted the most notable knowledge-gap in participant composition was the lack of economic expertise and econometric impact analysis. Further, some participants viewed the process as still too time consuming, "a heavy tool for busy civil servants". Overall, in comparison to other energy sector workshops, the transition arena was considered superior by the participants (4.47 average), most of whom had participated in numerous such events before.

\subsection{Impacts and Early Outcomes}

Regarding learning by the participants, the TA was mostly considered successful, with variation in what was being learned. In the survey, learning scored 3.89 (average) and new idea generation 
3.75 (average). However, many possessed already a good understanding of energy transitions in general and the TA did not change perceptions of the phenomenon ( 2.79 average). In the interviews, some participants saw the TA as contributing to broader learning they were experiencing in terms of sustainability transitions, benefitting from multiple different inputs and sources (not the TA alone). Others reported specific learning on, for example, home charging systems, demand response and heat networks. Three participants mentioned the novelty of the method and learning about the method as their key learning. Only two participants said that they had not benefitted in the form of direct learning. Nine participants did not get new ideas from the TA work, while fourteen mentioned ideas, for example, related to policy interactions, a new low-carbon program, use of the method in organizational strategy development, and the organization of stakeholder involvement in policy preparation.

Fifteen participants considered the arena work having a positive impact on their work at least to some extent, while six participants did not see any effects. One mentioning impact on own work said "ideas of pathways instead of goals has stuck", while a few said they had adopted a more systemic way of thinking. A participant from a non-governmental organisation (NGO) mentioned topics influencing their policy work directly, while the two participants from city councils reported impact on their current or future work.

One of the aims of the TA was also to create new connections between people enthusiastic about transitions. Out of the 21 participants interviewed, 16 reported new connections. Some had not yet resulted in any action, many mentioned ongoing discussions, while also a deepening of old contacts was mentioned. Two specific examples were raised: the participants from cities were consulted in the strategy work of the Ministry of the Environment and one concrete business idea had emerged.

Regarding the policy impact, the replies varied. Those participants following policy closely had identified clear connections in ministry-level policy preparation and impacts on the design of new funding tools and program work carried out in political parties. Two tangible results were directly credited to the TA process-a private-public partnership in urban energy experimentation and a legislative amendment of the renewable energy subsidy system. In the longer term, the respondents shared a cautious anticipation of the TA contributing to the 'tipping of scales' in favor of energy transitions (see Section 5) and several participants framed the Parliament elections of 2019 as a practical test for the suggested 'energy transitions agenda'.

The interviews also gauged the usefulness of the TA method in Finland more broadly and in other contexts. The replies were predominantly positive regarding the re-design and transport of TM methodologies between contexts. Finland, as small and consensus-oriented country with a tradition of stakeholder hearings and committee work was seen as an optimal arena for deliberative specialist work on a number of transition topics (e.g., urbanization, digitalization and culture). The approach was seen particularly to have potential for focused topical and geographical contexts.

\section{Discussion and Conclusions}

The following discusses and concludes our findings from a redesigned energy transition arena process, with focus on mid-range planning and construction of concrete change pathways. It will cover: (1) lessons drawn from participant evaluation; (2) how the redesigned TA process can contribute to meeting some of the challenges that have faced TM; and (3) further developments to TA.

Our contribution to transitions theory resides in adapting transition arenas to mid-range pathway development with considerably more concrete pathway steps and further pathway-step actions than have been hitherto pursued within TM. Associated with this, we contribute to adapting the TM schemata by anchoring it more firmly into policy contexts where long-term visions as well as experiments are already actively pursued with established functioning mechanisms, and where the redesigned mid-range TA process offers input to how to bridge the two and, in doing so, raises the ambition level also in the long-term and in further experiments to be envisioned. 


\subsection{Lessons Drawn in Participant Evaluation}

The following lessons can be drawn from our evaluation, regarding the process design and impact of transition arenas. First, the concrete and deliberative pathway formation process was beneficial to the TA, in terms of engaging the participants, benefitting from the diverse expertise present in the group resulting in novel combinations of steps and suggestions for more specific pathways. Many participants were enthusiastic about the pathway work, which also created improved legitimacy for the outcomes of the TA that were specific and versatile enough. However, in the short-term it is unclear to what extent the interrelated combination of change actions required by each pathway will be taken up. It is simply too early to assess this even when there are positive signs as documented in Sections 5 and 6 , and more specifically whether the policy pathways built into the broader transition pathways will be considered by those in power. Even with some observed impacts on policy preparation and party-political work, the adoption of individual steps which can be thus far observed is not as yet evidence of proceeding with further steps presented in the transition pathways.

Second, although the TA process was designed to communicate closely with and potentially challenge the existing strategy work, by providing lists of immediate actions with dedicated actors to enhance the traceability of policy impacts, the policy relevance was still seen to be a weak spot of the process in both evaluation rounds. However, transition arenas as deliberative instruments are geared towards moving participants beyond immediate policy concerns and election cycles towards more long-term convergence [21,22], and rather influence other means of policy deliberation and stakeholder involvement than become the dominating contributors to future policymaking. This in mind, the transition arena redesign sought to achieve policy relevance through anchoring the work with on-going policy processes and adopting a mid-range timespan but, as noted, the impact remains to be seen, even though it cautiously appears that the TA may have already contributed to opening some policy windows [31].

Third, the diversity of backgrounds of selected specialists was considered to be a positive feature, but their homogeneity in their orientation towards sustainable energy transitions less so. Engaging more with regime actors and incumbents would have resulted in quite a different design with more explicit controversies, and it would have run the risk of capture by incumbents as reported in the Netherlands (cf. $[25,28])$. Thus, the pro-transition participant selection to avoid the process becoming dominated by status-quo oriented incumbents was a conscious choice based on earlier TA experiences. We can hypothesize that the decision not to involve those incumbent policy and industry actors who have the strongest vested interest in current status quo directly in the arena-but only afterward in dialogues over its results-may delay the implementation of some pathway actions as some of these incumbent actors are also key resource holders. The degree to which regime actors should be invited remains an open question, potentially also calling for new arrangements in facilitating potentially more confrontational arena deliberations.

Finally, connecting to our first point, our evaluation showed that the participants found the methodology useful—and even pedagogical—in unpacking systemic interactions and interrelations that are usually concealed in practical policy and business work. The further development and re-design of the methodology on systemic interconnections and cross-pathway dynamics could increase its usability in different policy contexts.

\subsection{Meeting the Challenges in Taking Transition Theory and Practice Forward}

The aims of making transition management procedures and principles 'travel' to different contexts and making TA processes better in addressing the urgency in accelerating sustainability transitions call for more variety in how transition management is pursued $[2,30,38,39]$. The transition arena process for supporting the Finnish energy system transition is an example of such an effort. The adequacy of our design and the participant evaluation of its success can be discussed in relation to the topics raised by Voß et al [25] for evaluating and redesigning transition management. 
Goals: The focus on cross-sectoral implementation of the energy transition in the mid-range timespan could potentially lose sight of the overall transition and be dominated by a consideration of marketable technological solutions. This was avoided by a 'systemic' framing of energy issues in the background material with goals adapted from the National Energy and Climate Strategy of 2016. The tight focus on implementation was considered successful, though some of the participants called for an even stronger policy focus.

Organization of the transition arena: Many transition arenas have been dominated by incumbents. The design reduced this problem by deliberately aiming for diversity. The diversity of actors, inclusiveness and transparency regarding stakeholder selection principles were rated positively in the evaluation. The selection meant, however, that the results had to be conveyed separately to some key regime actors.

Role of visions: In an ideal TA, frontrunners construct visions that inform and precede strategy development and the design of experiments. However, if incumbents dominate the TA, also visions may become vague and watered down. The workshops devoted to visioning were not particularly highly rated in the evaluation, but the participants considered a raised ambition level important as it increased shared ownership of the process. The general transition agenda was eventually considered more central than the individual pathways and actions. This tension between specific results and recommendations and a deeper change in the thinking of the issues dealt with in the TA is a fundamental one that must be solved on a case-by-case basis.

Experimentation. In the original TM, the TA is expected to initiate and guide real world experiments with portfolios of options for alternative socio-technical systems. This makes the TA a unidirectional process. In our case the TA built on and referred to completed and ongoing experiments. The pathways produced propositions for new areas of real-world experiments to accelerate transitions but their implementation remained uncertain and was dependent on individual activities of the participants. Making the experimentalist agenda stronger in the TA would have called for partly different participants with command over resources, but given the limited duration of the $\mathrm{TA}$, generating general ideas for experimentation were probably the most feasible outcome.

Evaluation and Learning: The original TM assumes an evolutionary selection process, in which options for action prove their feasibility in the real-world context. The evaluation provides information on the potential to contribute to the transformative vision. Our TA process was geared to facilitate learning among participants, and society-wide learning only through the dissemination of its results on mid-range transition processes and governance. The participants reported learning related to the systemic nature of change as important. The evaluation provided additional insights on learning, networking, policy impacts and methodological tinkering to improve the TA. This represents a more modest agenda than the original-for the case of an energy transition it is, however, probably more realistic, since there are several parallel and partly overlapping processes contributing to the overall energy transition. An effort to contain them all within one TM-process for evaluation and learning would require huge resources for coordination and would most likely be captured by incumbents.

Sources of legitimacy: The original TM takes the goal of sustainable development as a normative justification. In practice, there is a need for more practical legitimacy that helps dealing with issues such as the contrasts between project timeframes and expectations, funding and resources, internal hierarchies and fragmentation [30]. In our case, the legitimacy of the TA rested on positioning it as a deliberative process referring to existing energy and climate governance structures that have included broad consultation procedures, and an emphasis on experimentation and pilots. The transition arena process, particularly focused on a 2030 mid-range implementation timespan, appeared promising for the hitherto missing connection between the visions and experimentation and offered a means for better anticipating, linking and learning in experiments. None of the participants questioned the legitimacy of the TA, and also incumbent actors that were not part of it welcomed the debate it generated.

Embedding in political context: The original TM was presented as an overall management tool that governments use to actually implement a transition. Kern and Howlett [28] noted, however, 
that, in the Dutch energy transition process, potentially incoherent, inconsistent and/or incongruent policy mixes emerged, contrary to the ideal. At the local level, inertia and resistance to change have been found to counteract the successful implementation of TM-inspired governance mechanisms [30]. In our case, the transition arena was embedded in Finnish national and policy context specifics (e.g., long-term planning history, energy system features), but was not launched as an overarching strategic management tool. This lowered expectations on what would be achieved and also reduced pressure on, for example, participating civil servants. It fostered creativity in reflection but the downside was that the TA could not influence policy making directly. In the current turbulent times in the field of energy and climate policies this is not only a disadvantage. The TA became free to suggest more radical actions. For example, the official goal in the 2016 national energy and climate strategy was that there should be around 250,000 vehicles running on 'alternative fuels' (electric, gas etc) by 2030. The TA explored pathways leading to 600,000 . Recently announced roadmap by the Ministry of Transport and Communications follows this path and even more radical options [45].

Participation process support: The effort put into the codesign tools, procedures and materials, and the regular feedback to the participant was considered critical for the TA process. The evaluation confirmed that the preparatory work had succeeded. The tools that were developed allow for further versions of the approach in different contexts, which has already started in three different settings. In general, this indicates that TM and TA processes could benefit considerably more from engagement with principles, means and tools developed in collaborative design [40].

\subsection{Developing the TA Further}

Overall, the redesign of TA process to bridge existing long-term policy visions and mid-range policy targets to already running experiments addresses a new increasingly relevant time-span in transition governance and provides a novel way to operationalize its key premises. It thus provides an addition to the toolsets and procedures available for transition governance. Particularly, the possibility it offers for a diverse groups of expert participants to directly formulate transition pathways amongst themselves (without transition analysts constructing them) provides a new layer to interactive learning on transitions. It potentially creates higher ownership of the constructed pathways than in cases where pathways pertain to precast scenarios or become constructed by transitions analysts.

The design choices pertaining to TA goals, organization, participation and process support and the role of visions were successful in enhancing the systemic orientation of the process and nurturing of transition protagonist identities within the participant group. This was further enhanced with a tighter focus on policy implementation. However, several participants called for an even stronger policy focus and policy output mechanisms than was achieved, indicating that participants wish to complement the traditional long-term orientation in transition governance and TM [13,21], with sharpened implementation timespans of not only 'immediate actions' but mid-range pathways that continue and motivate these more concretely. Regarding the short-term policy effects, the visibility of this and other transition agendas in the Finnish parliamentary elections and the new Government Program in 2019 will provide material for evaluating the outcome. Another source of information is the current Government's ongoing revision on the long-term climate plan that is due in early 2019. It is expected to aim for carbon neutrality by 2045 , which will require more ambitious goals also for 2030. The timing of these political processes offers a chance to follow whether and how the suggested policy goals and illustrated transition dynamics travel among the stakeholders, including the political parties. More generally, however, future TA's could place specific attention into how the creation of new policy pathways ties with the development of broader multi-stakeholder and cross-sectoral transition pathways. It is not surprising that less disruptive pathways face less resistance [47] than more disruptive ones; while governance models vary between centralized and dispersed [48].

The potential legitimacy problem for transition management was counteracted with several measures: having participants positioned in (though not officially representing) key institutions, having the national Innovation Fund Sitra to host the arena, and anchoring the work in current 
national energy and climate strategies to 2030 and 2050. These measures ensured legitimacy among the participants, and the positive assessment also carried over to their networks. However, the choice of participants, which has been an issue in TM processes from their very beginning, calls for continued trials, particularly regarding the degree of inclusion and exclusion of incumbent regime actors $[20,28]$. This is strongly related to the empowerment a TM process can achieve [23].

The mid-range timescale turned out to be appropriate in elaborating experiments and pilots to facilitate further learning. In the eight pathways, more than a hundred experiments and pilots were envisioned. Such open envisioning was made possible through the process not being hardwired to any policy processes [31], but, at the same time, their implementation is not guaranteed either. Setting up the 'interim visions and goals' for the mid-range allowed spelling out the transition targets for the different elements of the energy sector and helped formulate a 'transition agenda' out of the process. The overwhelming majority of participants considered the systematic use of co-design workshop techniques, supporting templates, skilled facilitators and custom-built pathway creation toolsets as very helpful in such an interactive and goal-oriented work. One can argue that this type of TA work would fit very well into the development of socio-technical scenarios that aim at exploring social and political feasibility in low-carbon transitions [49]. However, the workload was considerable in terms of time, materials and educated facilitation. Further development of the codesign procedures and tools and digital tools to support pathway creation, documentation and commentary should also be kept in the TA development agenda. These appear to hold considerable potential in enhancing TA processes and would ease their uptake in other contexts. Such work is underway in Finland and cross-cutting results can be expected in 2019-2020. Elements of the TA can find many uses from highly steered process to 'soft' applications, where the TA elements are used to support general deliberative processes. Variations in the pacing and timeslots for carrying through TA processes should be trialed to find sufficient but least time-consuming formats for different participant groups and contexts.

Author Contributions: Conceptualization, S.H., P.K., M.H., J.L., R.L.; Methodology, S.H., P.K., M.H., J.L., R.L.; Formal Analysis, S.H., P.K., M.H., J.L., R.L., T.M., A.T.; Investigation, S.H., J.L., P.K., T.M., R.L., K.A., M.H., A.T., S.P., M.R., A.P., J.P., K.S., L.H., K.M., T.H., A.B., M.P.; Data Curation, S.H., J.L., P.K., T.M., R.L., K.A., M.H., A.T., S.P., M.R., A.P, J.P., K.S., L.H., K.M., T.H., A.B., M.P.; Writing-Original Draft Preparation, S.H., P.K., M.H., J.L.; Writing-Review \& Editing, Visualization, S.H., T.M., S.P., J.L., P.K.; Supervision, S.H., R.L., M.P.; Project Administration and Funding Acquisition, R.L., A.T., S.H., M.H., P.K.

Funding: This work was supported the Strategic Research Council of Finland consortium 293405 "Smart Energy Transition: Realizing its potential for sustainable growth for Finland's second century" and Academy of Finland Grant 13289520 "Getting Collaborative Design Done".

Conflicts of Interest: The authors declare no conflict of interest.

\section{Appendix A}

Table A1. Process evaluation procedure (19/23 replies).

\begin{tabular}{ccc}
\hline Question & Scale & Results \\
\hline $\begin{array}{c}\text { 1. I received new ideas as result of arena work } \\
\begin{array}{c}\text { 2. I learned new things from } \\
\text { other participants }\end{array}\end{array}$ & $1(\min )-5(\max )(n=19)$ & mean: $3.89 /$ median: 4 \\
\hline $\begin{array}{c}\text { 3. My earlier view on energy transitions } \\
\text { was changed }\end{array}$ & $1(\min )-5(\max )(n=19)$ & mean: $2.79 /$ median: 3 \\
\hline 4. I found work worthwhile & $1(\min )-5(\max )(n=19)$ & mean: $4.21 /$ median: 4 \\
\hline 5. I found work inspiring & $1(\min )-5(\max )(n=19)$ & mean: $4.00 /$ median: 4 \\
\hline 6. Rate for visioning and system mapping & $1(\min )-5(\max )(n=19)$ & mean: $3.53 /$ median: 3 \\
\hline 7. Rate for pathway work & $1(\min )-5(\max )(n=18)$ & mean: $3.68 /$ median: 4 \\
\hline 8. Rate for final report & $1(\min )-5(\max )(n=19)$ & mean: $4.00 /$ median: 4 \\
\hline $\begin{array}{c}\text { 9. Organizing of transition arena in relation to } \\
\text { other energy workshops }\end{array}$ & $1(\min )-5(\max )(n=19)$ & mean: $4.47 /$ median: 5 \\
\hline
\end{tabular}


Table A1. Cont.

\begin{tabular}{|c|c|c|}
\hline Question & Scale & Results \\
\hline $\begin{array}{l}\text { 10. How comprehensive was the selection of } \\
\text { participants? What types of know-how } \\
\text { was missing? }\end{array}$ & Open field $(n=15)$ & $\begin{array}{l}\text { In general, very positive feedback; Economic expertise on } \\
\text { implications and effects was called upon }(4 / 19) \text { but } \\
\text { economic orientation was also challenged; sectoral } \\
\text { specialists on heat and transport services, more } \\
\text { involvement of MPs and inclusion of 'systemic specialist' } \\
\text { were mentioned }\end{array}$ \\
\hline $\begin{array}{l}\text { 12. Did your understanding on energy } \\
\text { transition, its phases, challenges and } \\
\text { drivers change? }\end{array}$ & Open field $(n=13)$ & $\begin{array}{l}\text { Most replies stated that the work strengthened, broadened } \\
\text { and diversified understanding on energy transitions and } \\
\text { its complexities though it didn't lead to drastic shift of } \\
\text { thinking }(8 / 13) \text {; yes }(2 / 13) ; \text { no }(3 / 13)\end{array}$ \\
\hline $\begin{array}{l}\text { 13. Positives and negatives on the } \\
\text { whole process }\end{array}$ & Open field $(n=12)$ & $\begin{array}{c}\text { Positive: participant selection and discussions (3), design of } \\
\text { process (8), level of facilitation (4), outcomes (1), topic (1) } \\
\text { Negative: time management (3); process (3); refinement and } \\
\text { mobilisation of outcomes (4) }\end{array}$ \\
\hline
\end{tabular}

Table A2. Impact evaluation procedure (21/23 replies).

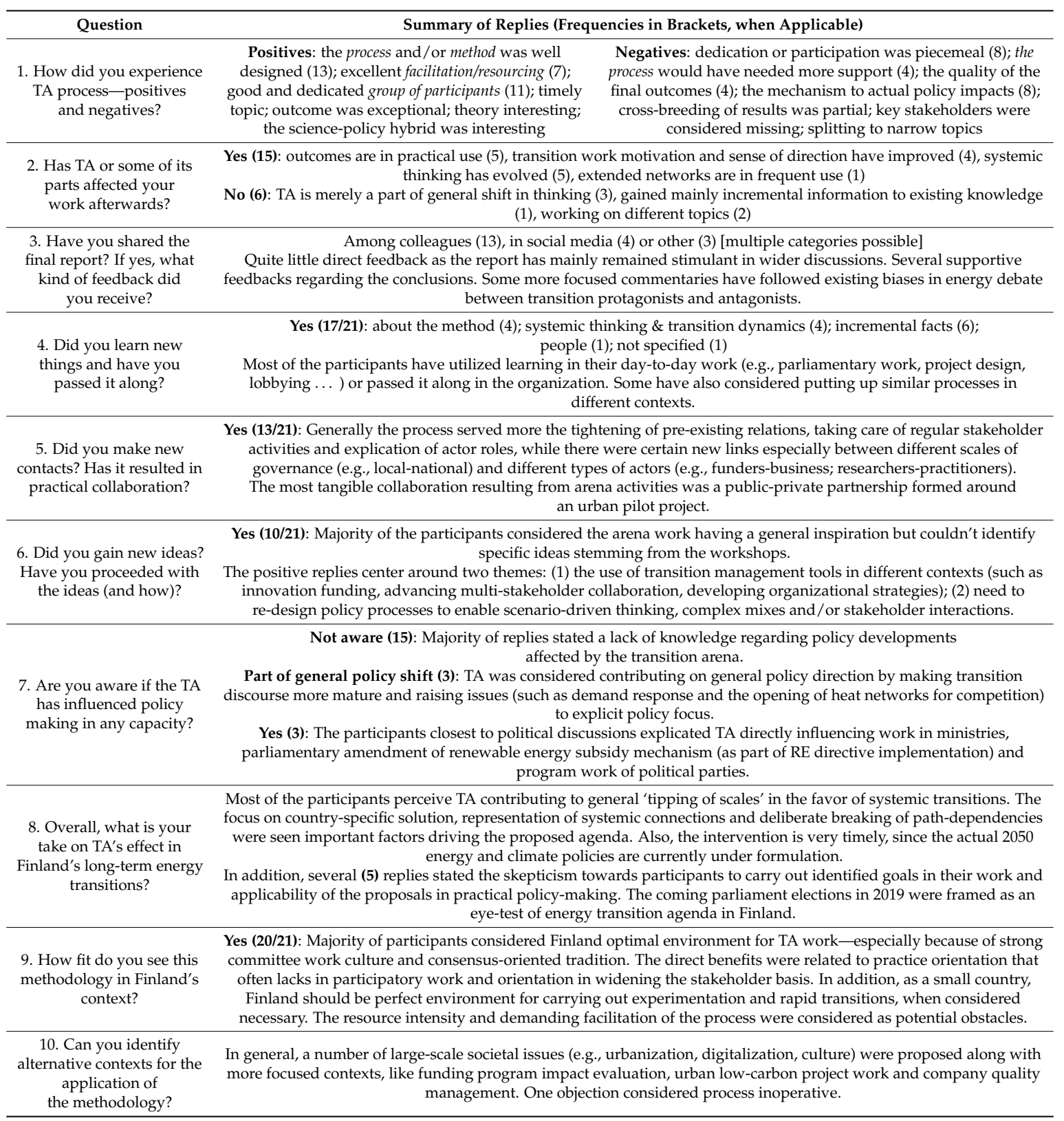


Table A3. Stakeholder categories and representatives.

\begin{tabular}{|c|c|}
\hline Stakeholder Category (No. of Participants) & Representatives \\
\hline Politicians (1) & $\begin{array}{l}\text { MP of the Coalition Party and chairman of the parliamentary "energy } \\
\text { renovation" group promoting the energy transitions politically }\end{array}$ \\
\hline Civil servants (national) (4) & $\begin{array}{l}\text { Representation of three ministries (economic affairs and employment; } \\
\text { environment; transport and communications) and energy authority }\end{array}$ \\
\hline Civil servants (cities) (2) & $\begin{array}{l}\text { Head of environment bureau and city commissioner from cities active } \\
\text { in energy transitions }\end{array}$ \\
\hline Transition entrepreneurs (3) & $\begin{array}{l}\text { Start-up companies in energy technology and electric transport sectors } \\
\text { and an energy sector company using disruptive business strategies }\end{array}$ \\
\hline Changemakers in incumbent companies (3) & $\begin{array}{l}\text { Representation from incumbent energy producer, multinational } \\
\text { technology company and retail sector company }\end{array}$ \\
\hline NGO's (1) & Climate and energy specialist from WWF Finland \\
\hline Active citizens (2) & $\begin{array}{l}\text { An active protagonist of citizen energy solutions and a vocal antagonist } \\
\text { of Finland's bioenergy-driven energy strategy }\end{array}$ \\
\hline Research institutes (1) & Finnish Environment Institute Syke \\
\hline Energy and innovation policy networks (2) & $\begin{array}{c}\text { Finnish Innovation Fund Sitra and Public Innovation Funding Agency } \\
\text { Tekes (Business Finland from 2018) }\end{array}$ \\
\hline Finance providers (2) & $\begin{array}{l}\text { Cleantech financial service company and a crowdfunding company } \\
\text { realizing low-carbon solution }\end{array}$ \\
\hline Low-carbon networks (2) & $\begin{array}{c}\text { Platform networks providing infrastructure for companies to scale up } \\
\text { clean climate and energy solutions }\end{array}$ \\
\hline
\end{tabular}

\section{References}

1. IPCC. Special Report: Global Warming of $1.5^{\circ} \mathrm{C}$; Intergovernmental Panel on Climate Change: Geneva, Switzerland, 2018.

2. Heiskanen, E.; Kivisaari, S.; Lovio, R.; Mickwitz, P. Designed to travel? Transition management encounters environmental and innovation policy histories in Finland. Policy Sci. 2009, 42, 409. [CrossRef]

3. Weber, K.M.; Rohracher, H. Legitimizing research, technology and innovation policies for transformative change: Combining insights from innovation systems and multi-level perspective in a comprehensive 'failures' framework. Res. Policy 2012, 41, 1037-1047. [CrossRef]

4. Sovacool, B.K. How long will it take? Conceptualizing the temporal dynamics of energy transitions. Energy Res. Soc. Sci. 2016, 13, 202-215. [CrossRef]

5. Alkemade, F.; Hekkert, M.; Negro, S. Transition policy and innovation policy: Friends of foes? Environ. Innov. Soc. Transit. 2011, 1, 125-129. [CrossRef]

6. Rogge, K.S.; Reichardt, K. Policy mixes for sustainability transitions: An extended concept and framework for analysis. Res. Policy 2016, 45, 1620-1635. [CrossRef]

7. Rosenbloom, D. Pathways: An emerging concept for the theory and governance of low-carbon transitions. Glob. Environ. Chang. 2017, 43, 37-50. [CrossRef]

8. Geels, F.W.; Schot, J. Typology of sociotechnical transition pathways. Res. Policy 2007, 36, 399-417. [CrossRef]

9. Bernstein, S.; Hoffmann, M. The politics of decarbonization and the catalytic impact of subnational climate experiments. Policy Sci. 2018, 51, 189-211. [CrossRef]

10. Hoogma, R.; Kemp, R.; Schot, J.; Truffer, B. Experimenting for Sustainable Transport-The Approach of Strategic Niche Management; Spon Press: London, UK, 2002; Volume 10.

11. Verbong, G.; Loorbach, D. (Eds.) Governing the Energy Transition: Reality, Illusion or Necessity? Routledge: New York, NY, USA, 2012.

12. Kivimaa, P.; Kern, F. Creative Destruction or Mere Niche Creation? Innovation Policy Mixes for Sustainability Transitions. Res. Policy 2016, 45, 205-214. [CrossRef]

13. Turnheim, B.; Berkhout, F.; Geels, F.; Hof, A.; McMeekin, A.; Nykvist, B.; van Vuuren, D. Evaluating sustainability transitions pathways: Bridging analytical approaches to address governance challenges. Glob. Environ. Chang. 2015, 35, 239-253. [CrossRef] 
14. Markard, J.; Raven, R.; Truffer, B. Sustainability transitions: An emerging field of research and its prospects. Res. Policy 2012, 41, 955-967. [CrossRef]

15. Kemp, R.; Loorbach, D. Transition management: A reflexive governance approach. In Reflexive Governance for Sustainable Development; Voß, J.-P., Bauknecht, D., Kemp, R., Eds.; Edward Elgar: Cheltenham, UK, 2006; pp. 103-130.

16. Kemp, R.; Loorbach, D.; Rotmans, J. Transition management as a model for managing processes of co-evolution towards sustainable development. Int. J. Sustain. Dev. World Ecol. 2007, 14, 78-91. [CrossRef]

17. Loorbach, D.; Rotmans, J. The practice of transition management: Examples and lessons from four distinct cases. Futures 2010, 42, 237-246. [CrossRef]

18. Frantzeskaki, N.; Wittmayer, J.; Loorbach, D. The role of partnerships in 'realising'urban sustainability in Rotterdam's City Ports Area, The Netherlands. J. Clean. Prod. 2014, 65, 406-417. [CrossRef]

19. Roorda, C.; Frantzeskaki, N.; Loorbach, D.; Van Steenbergen, F.; Wittmayer, J. Transition Management in Urban Context. Guidance Manual-Collaborative Evaluation Version; DRIFT, Erasmus University Rotterdam: Rotterdam, The Netherlands, 2012. Available online: http://acceleratingtransitions.eu/content/uploads/2014/03/ DRIFT-MUSIC-Transition-Management-In-Urban-Context.pdf (accessed on 15 January 2019).

20. Frantzeskaki, N.; Broto, V.C.; Coenen, L.; Loorbach, D. Urban Sustainability Transitions; Routledge: New York, NY, USA, 2017.

21. Loorbach, D. Transition management for sustainable development: A prescriptive, complexity-based governance framework. Governance 2010, 23, 161-183. [CrossRef]

22. Frantzeskaki, N.; Loorbach, D.; Meadowcroft, J. Governing societal transitions to sustainability. Int. J. Sustain. Dev. 2012, 15, 19-36. [CrossRef]

23. Hölscher, K.; Wittmayer, J.M.; Avelino, F.; Giezen, M. Opening up the transition arena: An analysis of (dis)empowerment of civil society actors in transition management in cities. Technol. Forecast. Soc. Chang. 2017. In Press. [CrossRef]

24. Hölscher, K.; Wittmayer, J.M. A German experience: The challenges of mediating 'ideal-type' Transition Management in Ludwigsburg. In Co-Creating Sustainable Urban Futures. A Primer on Applying Transition Management in Cities; Frantzeskaki, N., Hölscher, K., Bach, M., Avelino, F., Eds.; Springer: Dordrecht, The Netherlands, 2018; pp. 205-224.

25. Voß, J.-P.; Smith, A.; Grin, J. Designing long-term policy: Rethinking transition management. Policy Sci. 2009, 42, 275-302. [CrossRef]

26. Publications of the Ministry of Economic Affairs and Employment 50/2014. In Energy and Climate Roadmap 2050 Report of the Parliamentary Committee on Energy and Climate Issues; 2014. Available online: https:/ / tem.fi/documents/1410877/3437254/Energy+and+Climate+Roadmap+2050+14112014.pdf (accessed on 15 January 2019).

27. Publications of the Ministry of Economic Affairs and Employment 12/2017. In Government Report on the National Energy and Climate Strategy for 2030; 2017. Available online: http:/ / urn.fi/URN:ISBN:978-952-327199-9 (accessed on 15 January 2019).

28. Kern, F.; Howlett, M. Implementing transition management as policy reforms: A case study of the Dutch energy sector. Policy Sci. 2009, 42, 391-408. [CrossRef]

29. Kivisaari, S.; Lovio, R.; Väyrynen, E. Managing Experiments for Transition: Examples of Societal Embedding in Energy and Health Sectors; Elzen, B., Geels, F.W., Green, K., Eds.; Edward Algar: Chaltenham, UK, 2004.

30. Nagorny-Koring, N.C.; Nochta, T. Managing urban transitions in theory and practice-The case of the Pioneer Cities and Transition Cities projects. J. Clean. Prod. 2018, 175, 60-69. [CrossRef]

31. Harlow, J.; Johnston, E.; Hekler, E.; Yeh, Z. Fostering Sustainability Transitions by Designing for the Convergence of Policy Windows and Transition Arenas. Sustainability 2018, 10, 2975. [CrossRef]

32. Voß, J.-P.; Amelung, N. Innovating public participation methods: Technoscientization and reflexive engagement. Soc. Stud. Sci. 2016, 46, 749-772. [CrossRef] [PubMed]

33. Government Programme, 2015. Valtioneuvosto. Available online: https://valtioneuvosto.fi/documents/ 10184/1427398/Ratkaisujen+Suomi_EN_YHDISTETTY_netti.pdf/8d2e1a66-e24a-4073-8303-ee3127fbfcac/ Ratkaisujen+Suomi_EN_YHDISTETTY_netti.pdf.pdf (accessed on 26 September 2018).

34. Energia Kokeilut: Uuden Energian kokeilut Suomessa. Available online: http://energiakokeilut.fi/ (accessed on 4 January 2019). 
35. Kivimaa, P. Government-affiliated intermediary organisations as actors in system-level transitions. Res. Policy 2014, 43, 1370-1380. [CrossRef]

36. Mûller, M.J.; Wildman, D.M.; White, E.A. Taxonomy of PD practices: A brief practitioner's guide. Commun. ACM 1993, 36, 26-28.

37. Eriksen, M.A.; Brandt, E.; Mattelmäki, T.; Vaajakallio, K. Taking design games seriously: Re-connecting situated power relations of people and materials. In Proceedings of the 13th Participatory Design Conference, Windhoek, Namibia, 6-10 October 2014; Volume 1, pp. 101-110.

38. Gaziulusoy, A.İ.; Ryan, C. Roles of design in sustainability transitions projects: A case study of Visions and Pathways 2040 project from Australia. J. Clean. Prod. 2017, 20, 1297-1307. [CrossRef]

39. Gaziulusoy, A.İ.; Ryan, C. Shifting Conversations for Sustainability Transitions Using Participatory Design Visioning. Des. J. 2017, 20, 1916-1926. [CrossRef]

40. Hyysalo, S.; Perikangas, S.; Marttila, T.; Auvinen, K. Catalysing pathway creation for transition governance. In Proceedings of the 51th International Conference on Design Research Society, Limeric, Ireland, 25-28 June 2018.

41. Ferguson, B.C.; Brown, R.R.; Frantzeskaki, N.; de Haan, F.J.; Deletic, A. The enabling institutional context for integrated water management: Lessons from Melbourne. Water Res. 2013, 47, 7300-7314. [CrossRef] [PubMed]

42. Hodgson, A.M. Hexagons for systems thinking. Eur. J. Oper. Res. 1992, 59, 220-230. [CrossRef]

43. Hyysalo, S.; Marttila, T.; Temmes, A.; Lovio, R.; Kivimaa, P.; Auvinen, K.; Pyhälammi, A.; Lukkarinen, J.; Peljo, J. New Perspectives to Energy Transition in Finland-Ambitious Energy and Climate Actions for the Years 2018-2030 Envisoned by Transition Arena; Aalto Yliopisto: Helsinki, Finland, 2017.

44. Helen: Avoin Kaukolämpö. Available online: https://www.helen.fi/lampo/yritykset/avoin-kaukolampo/ (accessed on 4 January 2019).

45. Särkijärvi, J.; Jääskeläinen, S.; Lohko-Soner, K. (Eds.) Carbon-Free Transport by 2045-Paths to an Emission-Free Future-Interim Report by the Transport Climate Policy Working Group Publications of the Ministry of Transport and Communications 9/2018. Abstract in English. Available online: http:/ / urn.fi/URN:ISBN:978-952-243-555-2 (accessed on 15 January 2019). (In Finnish)

46. Schäpke, N.; Omann, I.; Wittmayer, J.; van Steenbergen, F.; Mock, M. Linking Transitions to Sustainability: A Study of the Societal Effects of Transition Management. Sustainability 2017, 9, 737. [CrossRef]

47. Markard, J.; Suter, M.; Ingold, K. Socio-technical transitions and policy change-Advocacy coalitions in Swiss energy policy. Environ. Innov. Soc. Transit. 2016, 18, 215-237. [CrossRef]

48. Byskov Lindberg, M.; Markard, J.; Andersen, D. Policies, actors and sustainability transition pathways: A study of the EU's energy policy mix. Res. Policy 2018, in press. [CrossRef]

49. Geels, F.W.; McMeekin, A.; Pfluger, B. Socio-technical scenarios as a methodological tool to explore social and political feasibility in low-carbon transitions: Bridging computer models and the multi-level perspective in UK electricity generation (2010-2050). Technol. Forecast. Soc. Chang. 2018, in press. [CrossRef]

(C) 2019 by the authors. Licensee MDPI, Basel, Switzerland. This article is an open access article distributed under the terms and conditions of the Creative Commons Attribution (CC BY) license (http://creativecommons.org/licenses/by/4.0/). 